\title{
Personalised glucose therapy: glucose targets in critically ill patients with pre-existing poorly controlled type 2 diabetes
}

\author{
P Kar ${ }^{1,2^{*}}$, MP Plummer ${ }^{1,2}$, R Bellomo $^{3}$, AJ Jenkins ${ }^{4}$, AS Januszewski ${ }^{4}$, K Lange $^{5,6}$, MJ Chapman ${ }^{1,2,6}$, M Horowitz ${ }^{5,6}$, \\ AM Deane ${ }^{1,2,6}$
}

From ESICM LIVES 2015

Berlin, Germany. 3-7 October 2015

\section{Introduction}

In patients without pre-existing diabetes, hyperglycaemia during critical illness is associated with adverse outcomes. However, recent observational data suggest that in patients with pre-existing poorly controlled type 2 diabetes (defined as an HbA1c $\geq 7 \%$ ) prior to their acute illness, targeting glucose concentrations $<10 \mathrm{mmol} / \mathrm{l}$ is associated with harm [1]. Accordingly a higher glucose target may benefit these patients.

\section{Objectives}

To determine whether more liberal glucose targets in critically ill patients with pre-existing poorly controlled type 2 diabetes increases time weighted mean glucose concentration, attenuates hypoglycaemia, and appears overtly safe.

\section{Methods}

Prospective, open-label, sequential period, pilot study of 86 patients with poorly controlled type 2 diabetes (admission HbA1c $\geq 7.0 \%$ ) and a blood glucose concentration > $10 \mathrm{mmol} / \mathrm{L}$ requiring admission to the Intensive Care Unit (ICU) and administration of insulin. The 'control' patients $(\mathrm{n}=53)$ were consecutively admitted during a 6 month period and the 'intervention' patients $(n=33)$ were admitted during a subsequent 6 month period. During the 'control' period blood glucose was targeted between $6-10 \mathrm{mmol} / \mathrm{l}$, whereas during the 'intervention' period the target was $10-14 \mathrm{mmol} / \mathrm{l}$. Time weighted mean glucose was calculated and recorded blood glucose concentrations < $4.0 \mathrm{mmol} / \mathrm{l}$ considered as an hypoglycaemic episode for each patient. Data are mean (SE) or median [IQR] and

\footnotetext{
${ }^{1}$ Royal Adelaide Hospital, Intensive Care Unit, Adelaide, Australia
} Full list of author information is available at the end of the article analysed using independent samples t-test, Mann-Whitney test, Chi-squared test, Linear and Logistic regression as appropriate.

\section{Results}

The groups were well matched in terms of age (Control: 64.0 (2.0) vs Intervention: 62.6 (2.0) years), admission HbA1c (8.5 (0.2) vs $8.8(0.2) \%)$, APACHE II score (20.4 (1.0) vs 20.5 (1.2)) and Charlson Comorbidity Index (4.5 $(0.3)$ vs $4.3(0.3))$. More liberal targets resulted in greater time weighted mean glucose concentrations (TWGluco$\mathrm{se}_{\text {day0-7 }} 9.3(0.3)$ vs $\left.10.2(0.4) \mathrm{mmol} / \mathrm{l}, \mathrm{P}=0.04\right)$ and there was a trend towards fewer patients with hypoglycaemic episodes ( $34 \%$ vs $16 \%$ of patients, $\mathrm{P}=0.07$ ). There was no difference in ICU mortality (10 [19\%] vs 6 [18\%], $\mathrm{P}=0.94)$ or 90 -day mortality $(19[36 \%]$ vs 12

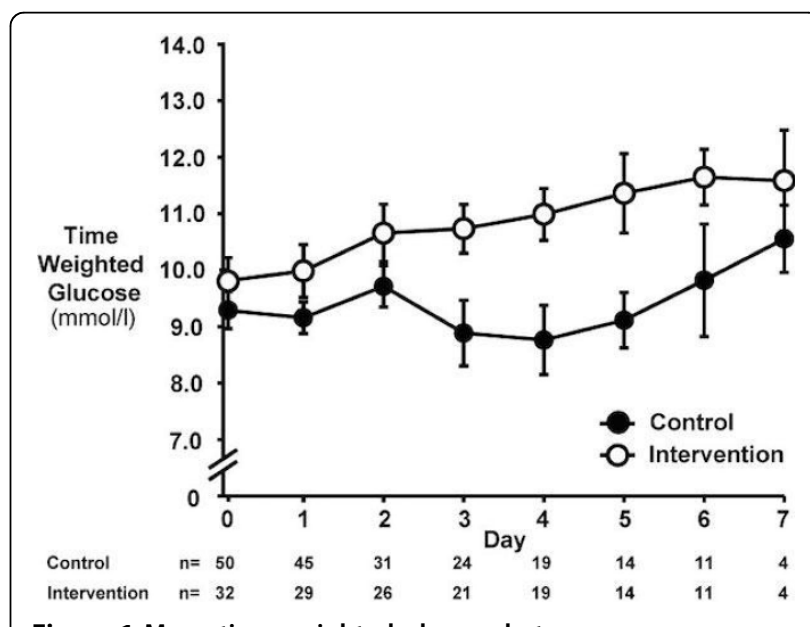

Figure 1 Mean time weighted glucose between groups.

(c) 2015 Kar et al.; This is an Open Access article distributed under the terms of the Creative Commons Attribution License (http:// creativecommons.org/licenses/by/4.0), which permits unrestricted use, distribution, and reproduction in any medium, provided the original work is properly cited. 
[36\%], $\mathrm{P}=0.96)$. ICU length of stay was shorter in the 'control' period (3.5 [4.0] vs 6.3 [8.7] days, $\mathrm{P}=0.01$ ) with significance persisting when adjusting for APACHE scores and Charlson Comorbidity Index $(\mathrm{P}=0.04)$.

\section{Conclusions}

In critically ill patients with pre-existing poorly controlled type 2 diabetes, more liberal glucose targets increase mean glucose concentrations may reduce the incidence of insulin- induced hypoglycaemia, and appear to be overtly safe. Prospective studies using larger cohorts are indicated.

\section{Grant Acknowledgment}

Dr Kar is supported by a Royal Adelaide Hospital A.R. Clarkson Scholarship

\section{Authors' details}

${ }^{1}$ Royal Adelaide Hospital, Intensive Care Unit, Adelaide, Australia. ${ }^{2}$ University of Adelaide, Discipline of Acute Care Medicine, Adelaide, Australia. ${ }^{3}$ The Austin Hospital, Intensive Care Unit, Melbourne, Australia. ${ }^{4}$ University of Sydney, NHMRC Clinical Trials Centre, Sydney, Australia. ${ }^{5}$ University of Adelaide, Discipline of Medicine, Adelaide, Australia. ${ }^{6}$ University of Adelaide, NHMRC Centre for Research Excellence, Adelaide, Australia.

Published: 1 October 2015

\section{Reference}

1. Plummer MP, Bellomo R, Cousins CE, et al: Dysglycaemia in the critically ill and the interaction of chronic and acute glycaemia with mortality. Intensive care Medicine 2014, 24:973-80.

doi:10.1186/2197-425X-3-S1-A290

Cite this article as: Kar et al:: Personalised glucose therapy: glucose targets in critically ill patients with pre-existing poorly controlled type 2 diabetes. Intensive Care Medicine Experimental 2015 3(Suppl 1):A290.

\section{Submit your manuscript to a SpringerOpen ${ }^{\circ}$ journal and benefit from:}

- Convenient online submission

- Rigorous peer review

- Immediate publication on acceptance

- Open access: articles freely available online

- High visibility within the field

- Retaining the copyright to your article

Submit your next manuscript at $>$ springeropen.com 